\title{
Current trend of utilization of new generation proton pump inhibitors in gastric disorders among people in Jessore city, Bangladesh
}

\author{
Debendra Nath Roy ${ }^{*}$, Nowrin Ferdiousi, Md.Uzzal Haque, Mosharraf Hossain, Sheikh Shahriar Rajib \\ Department of Pharmacy, Faculty of Biological Science and Technology, Jessore University of Science and Technology, Jessore-7408, Bangladesh.
}

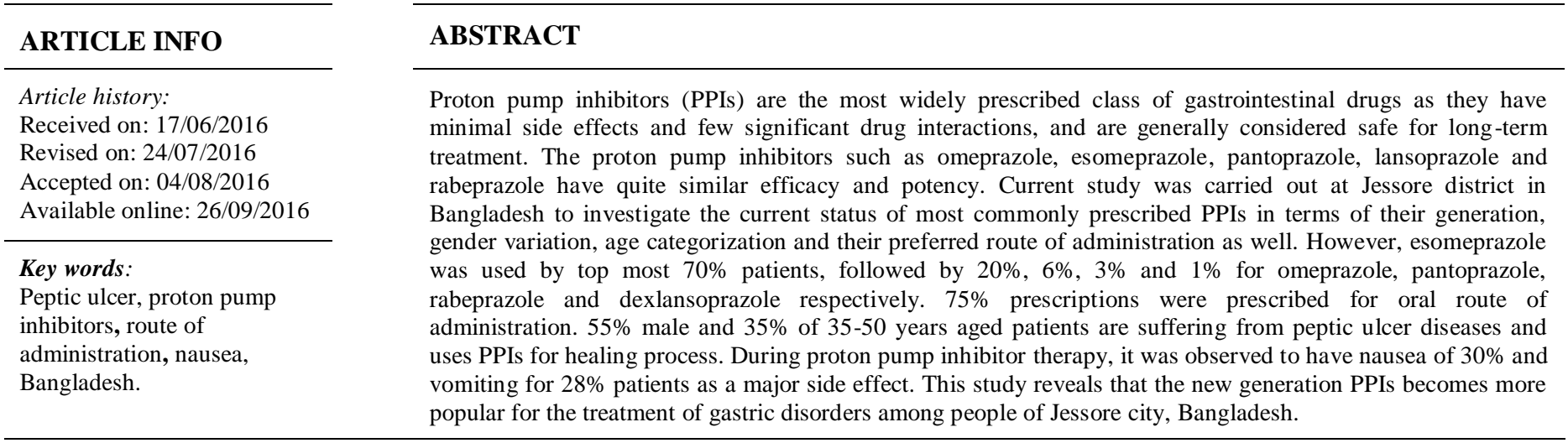

\section{INTRODUCTION}

Proton-pump inhibitors are a group of drugs whose main action is a pronounced and long-lasting reduction of gastric acid production. They are the most potent inhibitors of acid secretion available (Sachs et al., 2006). This group of drugs followed and largely superseded another group of medications with similar effects, but a different mode of action, called $\mathrm{H}_{2}$ receptor antagonists. PPIs are among the most widely sold drugs in the world, and the first one, omeprazole, is on the WHO Model List of Essential Medicines (WHO Model List of Essential Medicines, 2013). Proton pump inhibitors act by irreversibly blocking the hydrogen/potassium adenosine triphosphatase enzyme system (the $\mathrm{H}^{+} / \mathrm{K}^{+}$ATPase, or, more commonly, the gastric proton pump) of the gastric parietal cells (Zajac et al., 2013). The proton pump is the terminal stage in

\footnotetext{
* Corresponding Author

Debendra Nath Roy, Department of Pharmacy, Faculty of Biological Science and Technology, Jessore University of Science and Technology, Jessore-7408, Bangladesh.Email:dn.roy@ just.edu.bd
}

gastric acid secretion, being directly responsible for secreting $\mathrm{H}^{+}$ ions into the gastric lumen, making it an ideal target for inhibiting acid secretion. Targeting the terminal step in acid production, as well as the irreversible nature of the inhibition, results in a class of drugs that are significantly more effective than $\mathrm{H}_{2}$ antagonists and reduce gastric acid secretion by up to $99 \%$. Gastro esophageal reflux disease (GERD) can be diagnosed on the basis of the history alone in patients presenting with typical symptoms of heartburn, regurgitation, or both, especially after meals. PPIs are extremely effective acid suppressants, and it is likely that patients with GERD will respond to them. Physicians generally may assume that patients with typical symptoms who respond to PPI therapy have GERD (Vault and Castell, 1999; Spechler, 2000). Much of the morbidity and mortality arising from peptic ulcer disease (PUD) arises from rebleeding. In general, proton pump inhibitors are well tolerated, and the incidence of short-term adverse effects is relatively low. Long-term use of PPIs has been less studied than short-term use, and the lack of data makes it difficult to make definitive statements (Corleto et al., 2014). The range and occurrence of adverse effects are similar for all of the PPIs, though they have been reported more frequently with omeprazole. 
This may be due to its longer availability and, hence, clinical experience. Common adverse effects include headache, nausea, diarrhea, abdominal pain, fatigue, and dizziness (Rossi, 2006). Infrequent adverse effects include rash, itch, flatulence, constipation, anxiety, and depression. Also infrequently, PPI use may be associated with occurrence of myopathies, including the serious reaction rhabdomyolysis (Clark and Strandell, 2006). Another concern is the association between long-term PPI use and hypomagnesemia. In March 2011, the FDA issued an advisory warning that patients taking PPIs may be at risk for hypomagnesemia (www.fda.gov/drugs/drugsafety/ucm245011. htm). There have been 30 cases of severe hypomagnesemia reported in long-term PPI users that normalized after the PPI was discontinued. Although the mechanism is not known, in some patients, PPIs appear to interfere with active transport of magnesium across the intestinal wall or cause excessive loss into the intestinal lumen (Cundy and Mackay, 2011). It is therefore recommended that before initiating patients into PPIs for longterm therapy (1year) and when co administered with diuretics or digoxin, serum magnesium levels should be obtained and monitored periodically. The rate of omeprazole absorption is decreased by concomitant food intake. In addition, the absorption of lansoprazole and esomeprazole is decreased and delayed by food. It has been reported, however, that these pharmacokinetic effects have no significant impact on efficacy (Astra Zeneca Pty Ltd, 2005; Wyeth Australia Pty Ltd, 2004).

PPIs have a half-life in human blood plasma of only 6090 minutes, but because they covalently bind to the pump, the half-life of their inhibition of gastric acid secretion lasts an estimated 24 hours. Dissociation of the inhibitory complex is probably due to the effect of the endogenous antioxidant glutathione which leads to the release of omeprazole sulfide and reactivation of the enzyme (Shin et al., 2008 ; Carlsson, 2002). PPIs cause significant increases in gastric $\mathrm{pH}$, which may alter the absorption of weak acids or bases. They may inhibit the absorption of drugs such as griseofulvin, ketoconazole, itraconazole, iron salts, vitamin $\mathrm{B}_{12}$, cefpodoxime, and enoxacin, many of which are weak bases and require acid for absorption. However, co administration with these agents should be approached cautiously because it may result in clinical treatment failure (Welage and Berardi, 2000). This study therefore aims at scientifically investigate the pattern of new generation proton pump inhibitors use among people at Jessore city in Bangladesh

\section{MATERIALS AND METHODS}

\section{Study Design, Setting and Study Population}

The present research is a cross-sectional prospective study carried out in Jessore city in the district of Jessore under Khulna Division of Bangladesh. The data were collected during 31 December, 2015 to 31 March; 2016. From every patient single prescription was collected and took a snapshot of this prescription and information's were collected by conducting meeting with physicians, market promotional officers, workers of pharmacy shops, observing their daily sales of PPIs.

\section{Study Criteria}

1. Inclusion Criteria: Patients receiving PPIs drug treatment for peptic ulcer, gastritis, GERD. Patient receiving prophylactic PPI therapy during NSAID, antibiotics, steroids, etc.

2. Exclusion Criteria: Pregnant women.

\section{Data Collection}

Data were collected from various prescriptions and local pharmacy shops to carry out the survey. Total 400 prescriptions were collected directly from the patient of physician chamber and 35 local pharmacy shops were selected from different locations for data collection about daily selling of PPI. The data collectors were waiting in front of the pharmacy shop and convince them to produce their prescription data to the interviewers as well as participated in the interview session. The patients who were unconscious/mentally retarded, who were suffering with psychiatric diseases and who were admitted into hospitals were excluded from the study.

\section{STATISTICAL ANALYSIS}

Descriptive statistics were applied to the collected data using Microsoft Excel software. Simple statistical method (Bar diagram) was used to calculate the data and finally expressed in percentages.

\section{ETHICAL CONSIDERATIONS}

The study was conducted following the general principles (section 12) of WMA declaration of Helsinki. This survey based research is also logistically supported by the Department of Pharmacy, Jessore University of Science and Technology, Jessore in Bangladesh. The human subjects involved in this study did not use any hazardous agents and samples were not collected from them. As the human subjects only participated in the interview, this survey based research didn't take any further approval from institutional ethics committee.

\section{RESULTS AND DISCUSSION}

In gender categorization, it was found that $55 \%$ male patients used PPI as an anti ulcerant for healing acidity. 35-50 years aged people were more prone to use PPI and it was almost $35 \%$ of total, however the next one is $30 \%$ for $50-60$ years patients. In children age of 10-15 years the amount is $8 \%$ and in case of adult it is $12 \%$. The major side effect symptoms treated with PPI include nausea $30 \%$ patients, vomiting $28 \%$ patients, epigastric pain in $12 \%$ patients, heartburn $18 \%$ and others $12 \%$. From this study it is observed that currently the major prescriptions of PPIs in include esomeprazole $70 \%$, followed by omeprazole $20 \%$. On the other hand, for $6 \%, 3 \%$ and $1 \%$ for 
pantoprazole, rabeprazol and dexlansoprazole respectively. 25\% PPIs were prescribed for intravenous administration while remaining huge $75 \%$ were prescribed as oral dosage form among all. These results are shown below by figure 1, 23 and 4 respectively.

\section{\% OF DRUG USE IN MALE \& FEMALE}
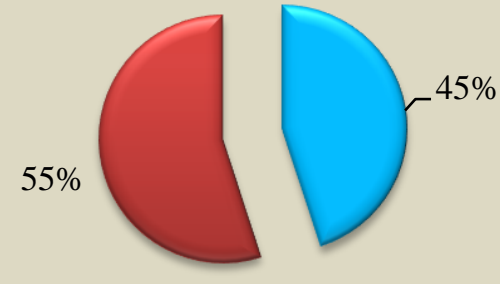

$\square$ Female

$\square$ Male

Fig 1: Percentage of drug used in male and female.

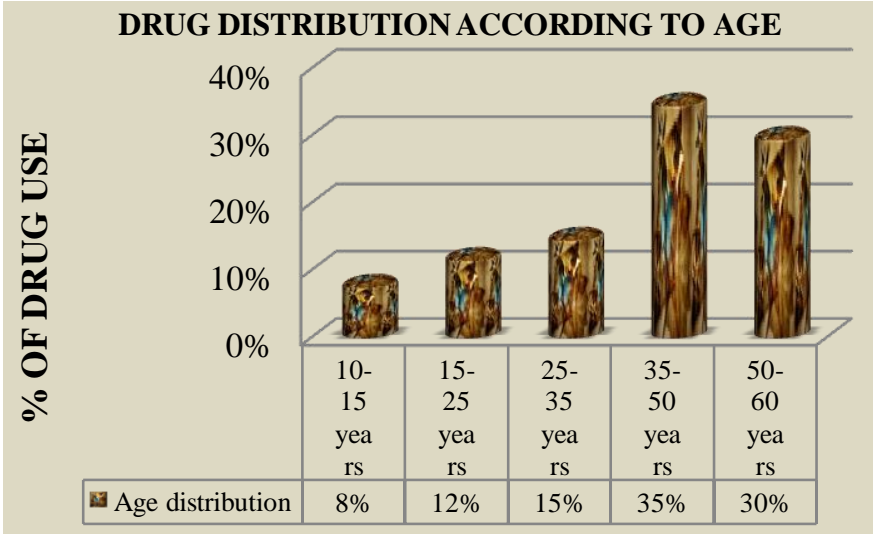

Fig 2: Percentage consumption of PPI with age variation.

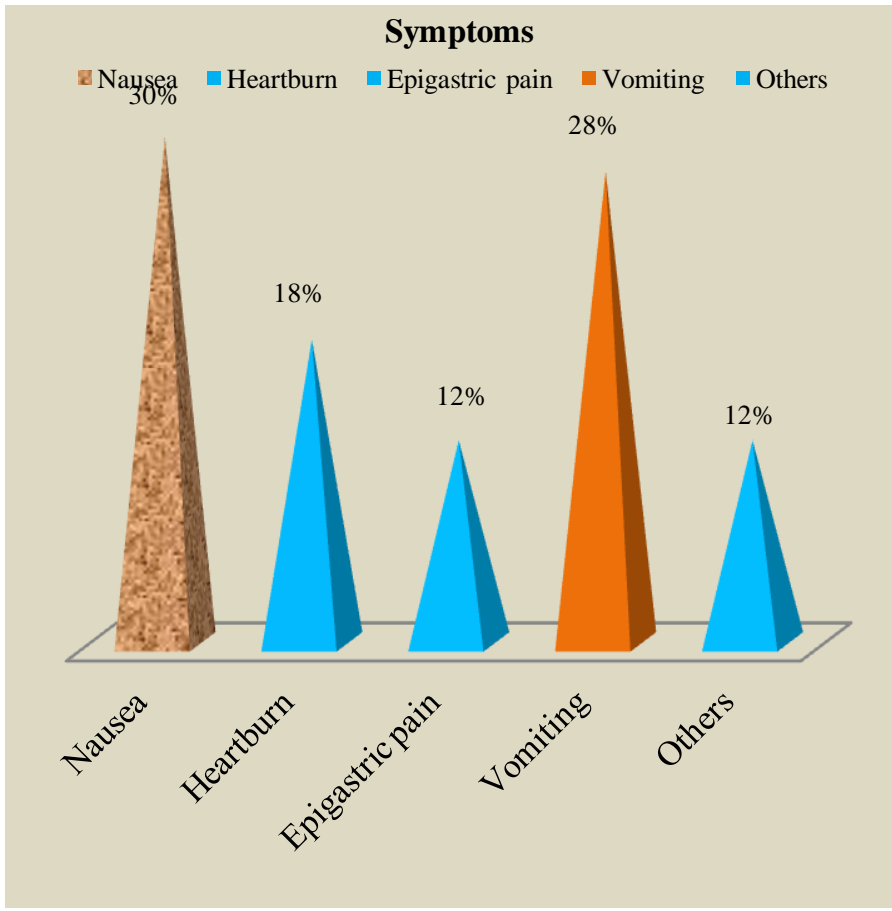

Fig 3: Remarkable side effects during PPI therapy.

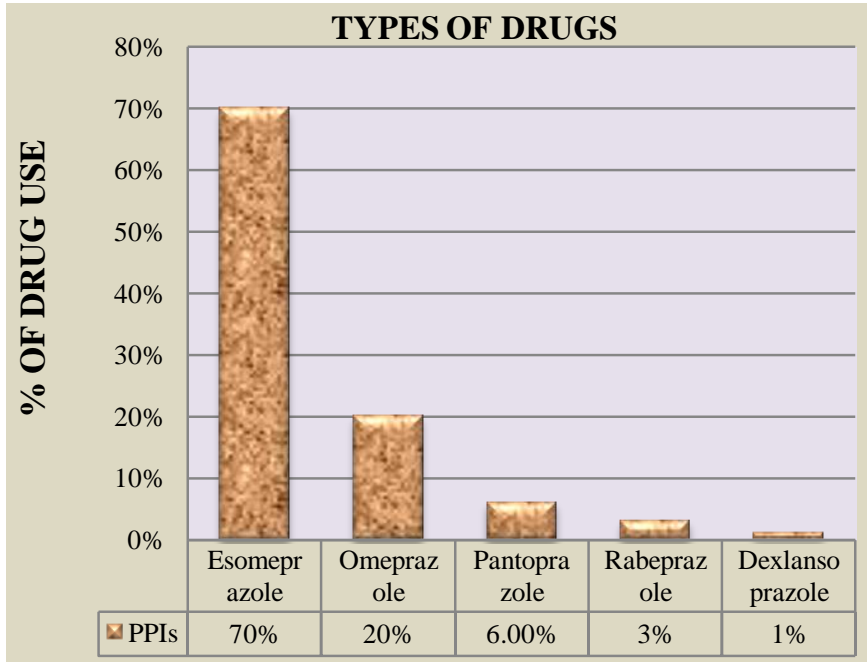

Fig 4: Percentage of various PPIs which are collected from patient's prescription.

\section{ROUTE OF ADMINISTRATION}

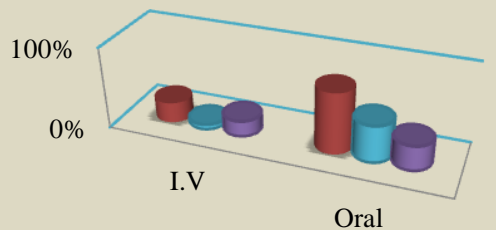

\begin{tabular}{|l|c|c|}
\cline { 2 - 3 } \multicolumn{1}{c|}{} & I.V & Oral \\
\hline $\begin{array}{c}\text { Route of } \\
\text { administration }\end{array}$ & $25 \%$ & $75 \%$ \\
\hline Male & $6 \%$ & $45 \%$ \\
\hline Female & $19 \%$ & $30 \%$ \\
\hline
\end{tabular}

Fig 5: Preferable route of PPI administration.

\section{CONCLUSIONS}

All PPIs appear to have similar efficacy in the treatment of various acid-peptic disorders. Absolute indications for PPI use include gastro esophageal reflux disease (GERD), peptic ulcer disease (PUD), chronic Non-Steroidal Anti Inflammatory Drugs (NSAIDs) use, treatment of $H$. pylori infection, and Erosive esophagitis (EE). Erosive esophagitis (EE) is a common complication in gastro esophageal reflux disease (GERD), accounting for approximately 20\% to $40 \%$ of cases. It is widely recognized that patients with EE develop complications (bleeding, strictures, and Barrett esophagus). PPIs provide healing of erosive esophagitis and relief of symptoms in patients with GERD, with intragastric $\mathrm{pH}>4.0$ positively correlating with healing of EE (Katz et al., 2007; Armstrong, 2004). A short course of PPI may be very helpful in selected patients but discontinuing PPI therapy should be considered in patients who are asymptomatic or about to 
receive broad-spectrum antibiotics known to have important. Decreased gastric acidity caused by PPI use has important implications for the survival of intestinal bacteria including enters pathogenic forms with potential to colonize, invade or inflame the intestine. PPI are probably overused and may be associated with significant health-care expenditure. The main action of PPIs is a pronounced and long-lasting effect on gastric acid production, which makes this class of drugs a highly effective treatment option for various acid-related disorders. However, their use has become very common and has expanded beyond the evidence base. This has led to increased drug costs and an evolving understanding of the adverse events associated with long-term use. Finally physicians and patients should balance the potential harms of PPI use against the expected benefits.

\section{ACKNOWLEDGEMENT}

We are grateful to all the reputed physicians, patients, market promotional officers of all pharmaceuticals, retail pharmacists of Jessore district for providing us the prescription information relating with potential PPI treatment.

\section{Financial support and sponsorship: Nil.}

Conflict of Interests: There are no conflicts of interest.

\section{REFERENCES}

Armstrong D. Gastric $\mathrm{pH}$-the most relevant predictor of benefit in reflux disease. Aliment Pharmacol Ther, 2004; 20:19Y26.

Astra Zeneca Pty Ltd. Nexium (Australian approved prescribing information). North Ryde: AstraZeneca; 2005.

Carlsson E, Lindberg P. Two of a kind. Chem Britain, 2002; 38(5):42-45.

Clark, DW; Strandell J. Myopathy including polymyositis: a likely class adverse effect of proton pump inhibitors? European J Clin Pharmacol, 2006; 62(6):473-479.

Corleto VD, Festa S, Di Giulio E, Annibale B. Proton pump inhibitor therapy and potential long-term harm. Curr Opin Endocrinol Diabetes Obes, 2014; 21(1):3-8.

Cundy T, Mackay J. Proton pump inhibitors and severe hypomagnesaemia. Curr Opin Gastroenterol, 2011; 27:180Y185.

DeVault KR, Castell DO. Updated guidelines for the diagnosis and treatment of gastroesophageal reflux disease. The Practice Parameters Committee of the American College of Gastroenterology. Am J Gastroenterol, 1999; 94:1434-42.
Food and Drug Administration. Drug safety communication: low magnesium levels can be associated with long-term use of proton pump inhibitor drugs (PPIs). www.fda.gov/drugs/drugsafety/ucm245011.htm. Published March 2, 2011.Accessed March 8, 2012.

Katz PO, Ginsberg GG, Hoyle PE, et al. Relationship between intragastric acid control and healing status in the treatment of moderate to severe erosive esophagitis. Aliment Pharmacol Ther, 2007; 25:617Y628.

Reilly JP. Safety profile of the proton-pump inhibitors. Am J Health Syst Pharm, 1999; 56 (23suppl 4):S11-7.

Rossi S, editor. Australian Medicines Handbook 2006. Adelaide: Australian Medicines Handbook; 2006. ISBN 0-9757919-2-3

Sachs G, Shin JM, Howden CW. Review article: The clinical pharmacology of proton pump inhibitors. Aliment Pharmacol Ther, 2006; 23:2-8.

Shin JM, Munson K, Vagin O, Sachs G. The gastric HKATPase: Structure, function, and inhibition. $\mathrm{Eu} \mathrm{J}$ Physiol, 2008; 457(3):609-22.

Spechler SJ. GERD and its complications. Mt Sinai J Med, 2000; 67:106-11

Welage LS, Berardi RR. Evaluation of omeprazole, lansoprazole, pantoprazole, and rabeprazole in the treatment of acidrelated diseases. J Am Pharm Assoc, 2000; 40:52-62.

"WHO Model List of EssentialMedicines" (PDF). World Health Organization. October 2013. Retrieved 22 April 2014.

Wyeth Australia Pty Ltd. Zoton (Australian approved prescribing information). Baulkham Hills: Wyeth; 2004.

Zajac P, Holbrook A, Super ME, Vogt M. An overview: current clinical guidelines for the evaluation, diagnosis, treatment, and management of dyspepsia. Ost Fam Phy, 2013; 5(2):79-85.

How to cite this article:

Roy DN, Ferdiousi N, Haque MU, Hossain M, Rajib SS. Current trend of utilization of new generation proton pump inhibitors in gastric disorders among people in Jessore city, Bangladesh. J App Pharm Sci, 2016; 6 (09): 153-156. 